\title{
Flower Bud Development and Chilling Requirements in Sweet Cherry cv 'Bing'
}

* Erica Fadón ${ }^{1,2}$, Maria Herrero ${ }^{1}$ and Javier Rodrigo ${ }^{2}$

${ }^{1}$ Departamento de Pomología, Estación Experimental Aula Dei, CSIC. Av. Montañana 1005, 50059 Zaragoza, Spain.

${ }^{2}$ Unidad de Fruticultura, Centro de Investigación y Tecnología Agroalimentaria (CITA). Av. Montañana 930, 50059 Zaragoza, Spain.

Keywords: Prunus avium, dormancy, flower development, starch, chilling requirements

\begin{abstract}
In order to survive to low temperatures, fruit trees in temperate regions stop their growth and enter dormancy. This is not just a survival strategy; chilling is also a prerequisite for adequate flowering. Chilling requirements are specific for each genotype and determine the possible geographical distribution of the different cultivars. In spite of the relevance of dormancy for fruit production, very little is known on the biological events during this time in flower buds, in which no visible changes can be observed until bud burst. In this work, flower bud development has been sequentially examined in sweet cherry (Prunus avium L.) cv "Bing" grafted on Santa Lucia 64 rootstock, in relation to dormancy and chilling accumulation. The work was performed over two consecutive years, paying attention to the possible anatomical and cytochemical changes accompanying dormancy. Results showed that, while no anatomical variations occurred along dormancy, conspicuous cytochemical changes could be tracked along this period that may help to understand the requirement for chilling.
\end{abstract}

\section{INTRODUCTION}

Fruit trees in temperate regions stop their growth and enter dormancy to survive low temperatures during winter. As occurs in other woody perennials, growth and dormancy cycles coordinate with the seasons (Rohde and Bhalerao, 2007). Blooming in sweet cherry, as in other temperate fruit trees, lasts for a few days only, but flower buds develop over months (Mounzer et al., 2008; Koutinas et al., 2010; Andreini et al., 2012). Flower differentiation takes place at the end of the previous summer. During the autumn flower bud development arrests and enters dormancy. This is not just a survival strategy to low temperatures, since chilling accumulation is also a prerequisite to resume growth (Coville, 1920; Knight, 1801) and adequate flowering (Perry, 1971). Chilling requirements are genetically regulated (Jansson and Douglas, 2007), and determine the possible geographical distribution of cultivars. In spite of the relevance of dormancy for fruit production, very little is known of the biological events during this process in reproductive buds, in which no visible changes can be observed until bud burst.

Chilling requirements have been empirically calculated by estimating the end of dormancy when the flower buds recovered their capacity to grow under favorable conditions in controlled chambers (Brown and Kotob, 1957; Ruiz et al., 2007; Alburquerque et al., 2008). A number of models have been developed to count the number of chilling hours $(\mathrm{CH})$, due to the fact that not all temperatures affect the plant in the same way (Guak and Neilsen, 2013). Early work based the records on the number 
of hours under $7.2^{\circ} \mathrm{C}\left(45^{\circ} \mathrm{F}\right)$ (Weinberger, 1950). Other models were later developed, to better fit different climatic regions, establishing a range of temperatures as the "UTAH Model” (Richardson et al., 1974), or the "Dynamic Model” (Fishman et al., 1987). Recently, research has focused on the genetic control of dormancy (Jimenez et al., 2010; Leida et al., 2012; Saito et al., 2013), but the interpretation of these data is hampered by the lack of knowledge of the biological processes underneath (Arora et al., 2003; Charrier and Améglio, 2011).

In sweet cherry, as it occurs in other histerant species, flower development took place in absence of leaves until blooming, so bud growth has to be supported by previously accumulated reserves in the tree (Ayala and Lang, 2015). Work in other Prunus species show the key role that starch accumulated in the pistil upon flower opening plays supporting the reproductive process (Rodrigo and Herrero, 1998; Rodrigo et al., 2000). In order to provide a frame to understand dormancy, the aim of this work was to characterize cherry flower bud development in relation to dormancy, paying attention to any possible changes in starch distribution in the flower along dormancy.

\section{MATERIALS AND METHODS}

Flower buds from three trees of sweet cherry (Prunus avium L.) cultivar "Bing” grafted on Santa Lucia 64 (Prunus mahaleb L.) rootstock were sampled weekly from middle September, before dormancy, to bloom, over two years (2011-2012 and 20122013). Trees were selected from a cultivar collection located at the Centro de Investigación y Tecnología Agroalimentaria de Aragón (CITA) in Montañana (Zaragoza) at a latitude $41^{\circ} 44^{\prime} 30^{\prime \prime} \mathrm{N}$, longitude $0^{\circ} 47^{\prime} 00^{\prime}$ ' W and $220 \mathrm{~m}$ altitude.

To characterize flower development, three fresh flower buds were monitored weekly under a stereomicroscope Leica MZ16 (Leica, Cambridge, UK) connected to a digital camera DFC320 (Leica, Cambridge, UK). In another set of three flower buds at phenological stage A (Baggiolini, 1952) or 50 by the BBCH code (Fadón et al., 2015), the starch content in the ovary was evaluated. For this purpose, the flower buds without scales were weekly fixed in ethanol: acetic acid 3:1 (v/v) (Williams et al., 1999), embedded in paraffin wax, and sectioned at $10 \mu \mathrm{m}$ with a Leica Jung 2045 rotatory microtome (Leica, Cambridge, UK). Starch content in the ovary was evaluated in two flowers per bud, resulting in six flowers per collecting day from the establishment of dormancy, when flower buds were closed and covered by dark brown scales at phenological stage A (Baggiolini, 1952) or BBCH code 50 (Fadón et al., 2015), to bud burst. Starch were quantified by using an image analysis system fitted to the microscope (Rodrigo et al., 1997). For this purpose, the sections were stained with I2KI (Johansen, 1940) for 5-10 min and observed under a DM 2500 microscope (Leica, Cambridge, UK). Images were taken with a DC-300 camera (Leica, Cambridge, UK) connected to the microscope. Image processing was done using an Image Analysis System Quantiment 550 (Leica, Cambridge, UK). Data of starch content were analyzed with one-way ANOVA, followed by Duncan's multiple-range test. Statistical analysis was performed with the SPSS software (SPSS Inc., Chicago, IL, USA).

The date of chilling fulfillment was estimated by counting the number of $\mathrm{CH}$ from $1^{\text {st }}$ October (Weinberger, 1950) until reaching 1000-1100 $\mathrm{CH}$, which are considered the chilling requirements of cv. "Bing" in our conditions (Tabuenca, 1983). This occurred approximately 3-4 weeks before full bloom. Daily records of temperature were registered in a meteorological station placed at the research center.

\section{RESULTS AND DISCUSSION}




\section{Dormancy Stage}

Flower induction took place during the summer and flower buds kept on growing during the autumn when flower buds were at phenological stage A (Baggiolini, 1952) or BBCH code 50 (Fadón et al., 2015), consistently with previous observations in sour cherry (Guimond et al., 1998). Flowers remained in the same developmental stage from the autumn until budbreak. This developmental stage was characterized by all floral whorls differentiated, sepals, petals, stamens and pistil. The pistil presented a characteristic green color, and it was possible to distinguish the incipient parts of the pistil: ovary, style and stigma. Anthers were translucent and with no filament (Fig. 1A).

Subsequent histological work allowed characterizing anther and pistil development during dormancy. Anthers presented the four locules, and the different anther layers were already differentiated: sporogenus tissue, tapetum, middle layers and epidermis (Fig. 1B). Ovules could not be observed, but it was possible to distinguish the precursor tissue of the obturator (Fig. 1C). This characterization of flower buds during dormancy seems to be consistent with dormant flower buds of apricot (Prunus armeniaca L.) (Julian et al., 2011; Andreini et al., 2012) and sour cherry (Prunus cerasus L.) (Felker et al., 1983). However, in gymnosperms, as Tsuga heterophylla and Chamaeccyparis nootkatensis, different stages of stamen development could be observed during dormancy (Sedgley and Griffin, 1989; Mirgorodskaya et al., 2015).

\section{Starch in the Flower Bud}

During dormancy no anatomic differences could be observed in flower buds. However, starch accumulated in the different bud structures in this period. Variations in starch content of flower buds have been also detected in sour cherry (Felker et al., 1983) and apricot (Julian, 2008). Starch quantification in cherry flower buds showed that starch accumulation was not constant during dormancy, but followed a particular pattern in which important differences were detected in each phase of dormancy. As flower buds entered dormancy, just starch traces were detected (Fig. 2A). A progressive starch accumulation was observed in the next weeks until mid-January, concomitantly with the accumulation of $\mathrm{CH}$ (Fig. 2B, 2C). Then, starch decreased gradually until bloom (Fig. 2D). Thus, an important accumulation of starch in the pistil took place during dormancy. Maximum starch accumulation in January was some thirty times more than the one recorded at the end of September, when flower buds were closed and covered by dark brown scales at phenological stage A (Baggiolini, 1952) or BBCH code 50 (Fadón et al., 2015). Evolution of starch content during dormancy could be a conserved process in other Prunus sp., since a similar pattern has been described in apricot (Julian, 2008). These changes observed in starch content support the idea that while no growth took place, flower buds were physiologically active (Luna et al., 1991; Rohde and Bhalerao, 2007; Sedgley and Griffith, 1989).

These results show clearly that the pattern of flower bud development was similar for the two years studied: flower buds entered dormancy and remained dormant at the same stage of development, with all the floral whorls differentiated. Although no anatomical or morphological changes were apparent during dormancy, flower buds were physiologically active, and starch gradually accumulated in the ovary, reaching a maximum value at the end of dormancy. These results set a framework that contributes to understanding the biological processes that take place in flower buds during dormancy.

\section{ACKNOWLEGEMENTS}


This work was supported by Ministerio de Economía y Competitividad (MINECO) - European Regional Development Fund, European Union (Project grants: AGL2012-40239-C02, INIA RFP2012-00017-C03 and INIA RTA2014-00085-00-00) by Grupo de Investigación de Aragón A-43 (Gobierno de Aragón-European Social Fund). E. F. was supported by the Ministerio de Economía y Competitividad by a doctoral fellowship (FPI BES-2010-037992).

\section{Literature cited}

Alburquerque, N., García-Montiel, F., Carrillo A., Burgos L. 2008. Chilling and heat requirements of sweet cherry cultivars and the relationship between altitude and the probability of satisfying the chill requirements. Environ. Exp. Bot. 64: 162170.

Andreini, L., Viti, R., Bartolini, S., Ruiz, D., Egea, J., Campoy, J.A. 2012. The relationship between xylem differentiation and dormancy evolution in apricot flower buds (Prunus armeniaca L.): The influence of environmental conditions in two Mediterranean areas. Trees-Struct. Funct. 26: 919-928.

Arora, R., Rowland, L.J., Tanino, K. 2003. Induction and release of bud dormancy in woody perennials: a science comes of age. HortScience 38: 911-921.

Ayala, M., Lang, G. 2015. ${ }^{13}$ C-Photoassimilate partitioning in sweet cherry during early spring. Cienc. Investig. Agrar. 42(2):191-203.

Baggiolini, M. 1952. Les stades repérés des arbres fruitiers à noyau. Rev. Rom. d'agric. Vitc. d'aboric. 8:3-4.

Brown, D.S. and Kotob, J.F. 1957. Growth of flower buds of apricot, peach and pear during the rest period. Proc. Amer. Soc. Hort. Sci. 69:158-164.

Charrier, G., Améglio, T. 2011. The timing of leaf fall affects cold acclimation by interactions with air temperature through water and carbohydrate contents. Environ. Exp. Bot. 72: 351-357.

Coville, F.V. 1920. The influence of cold in stimulating the growth of plants. P. Natl. Acad. Sci. USA 6:434-435.

Fadón, E., Herrero, M. and Rodrigo, J. 2015. Flower development in sweet cherry framed in the BBCH scale. Sci. Hortic. 192:141-147.

Felker, F.C., Robitaille, H.A. and Hess, F.D. 1983. Morphological and ultrastructural development and starch accumulation during chilling sour cherry flower buds. Am. J. Bot. 70:376-386.

Fishman, S., Erez, A. and Couvillon, G.A. 1987. The temperature-dependence of dormancy breaking in plants - Mathematical analisis of a 2-step model involving a cooperative transition. J. Theor. Biol. 124:473-483.

Guak, S, Neilsen, D. 2013. Chill unit models for predicting dormancy completion of floral buds in apple and sweet cherry. Hortic. Environ. Biote. 54: 29-36.

Guimond, C.M., Andrews, P.K. and Lang, G.A. 1998. Scanning electron microscopy of floral initiation in sweet cherry. J. Am. Soc. Hortic. Sci. 123:509-512.

Jansson, S. and Douglas, C.J. 2007. Populus: A model system for plant biology. Annu. Rev. Plant Biol. 58:435-458.

Jimenez, S., Li, Z., Reighard, G.L. and Bielenberg, D.G. 2010. Identification of genes associated with growth cessation and bud dormancy entrance using a dormancyincapable tree mutant. BMC Plant. Biol. 10.

Johansen, D.A. 1940. Plant microtechnique. In: M. Graw-Hill (ed.). New York, EEUU.

Julian, C. 2008. Diferenciación floral y cuajado de fruto en albaricoquero (Prunus armeniaca L.). Universidad de Zaragoza, Zaragoza. 
Julian, C., Rodrigo, J. and Herrero, M. 2011. Stamen development and winter dormancy in apricot (Prunus armeniaca). Ann. Bot. 108:617-625.

Koutinas, N., Pepelyankov, G., Lichev, V. 2010. Flower induction and flower bud development in apple and sweet cherry. Biotechnol. Biotechnol. Eq. 24: 15491558.

Knight, A. 1801. Account of some experiments on the ascent of the sap in trees. Phil. Trans. R. Soc. London 91:333-353.

Leida, C., Romeu, J.F., Garcia-Brunton, J., Rios, G. and Badenes, M.L. 2012. Gene expression analysis of chilling requirements for flower bud break in peach. Plant Breed. 131:329-334.

Luna, V., Reinoso, H., Lorenzo, E., Bottini, R. and Abdala, G. 1991. Dormancy in peach (Prunus persica L.) flower buds. 2. Comparative morphology and phenology in floral and vegetative buds, and the effect of chilling and giberellinA3. Trees-Struct. Funct. 5:244-246.

Mirgorodskaya, O.E., Koteyeva, N.K., Volchanskaya, A.V., Miroslavov, E. 2015. Pollen development in Rhododendron in relation to winter dormancy and bloom time. Protoplasma.

Mounzer, O.H., Conejero, W., Nicola, E., Abrisqueta, I., Tapia, L.M., Vera, J., Abrisqueta, J.M., Ruiz, M.C. 2008. Growth pattern and phenological stages of early-maturing peach trees under a mediterranean climate. HortScience 43: 1813-1818.

Perry, T.O. 1971. Dormancy of trees in winter. Science 171:29-36.

Richardson, E.A., Seeley, S.D. and Walker, D.R. 1974. A model for estimating the completion of rest for "Redhaven" and "Elberta" peach trees. Hortscience 9:331332.

Rodrigo, J. and Herrero, M. 1998. Influence of intraovular reserves on ovule fate in apricot (Prunus armeniaca L.). Sex. Plant Reprod. 11:86-93.

Rodrigo, J., Hormaza, J.I. and Herrero, M. 2000. Ovary starch reserves and flower development in apricot (Prunus armeniaca). Physiol. Plant. 108:35-41.

Rodrigo, J., Rivas, E. and Herrero, M. 1997. Starch determination in plant tissues using a computerized image analysis system. Physiol. Plant. 99:105-110.

Rohde, A. and Bhalerao, R.P. 2007. Plant dormancy in the perennial context. Trends Plant Sci. 12:217-223.

Ruiz, D., Campoy, J.A., Egea, J. 2007. Chilling and heat requirements of apricot cultivars for flowering. Environ. Exp. Bot. 61: 254-263.

Saito, T., Bai, S.L., Ito, A., Sakamoto, D., Ubi, B.E., Imai, T. and Moriguchi, T. 2013. Expression and genomic structure of the dormancy-associated MADS box genes MADS13 in Japanese pears (Pyrus pyrifolia Nakai) that differ in their chilling requirement for endodormancy release. Tree Physiol. 33:654-667.

Sedgley, M. and Griffith, A.R. 1989. Sexual Reproduction of Tree Crops. In: A. Press (ed.). London, United Kingdom.

Tabuenca, M.C. 1983. Necesidades de frío invernal de variedades de cerezo. Estacion Experimental de Aula Dei:661-667.

Weinberger, J.H. 1950. Chilling requirements of peach varieties. Proc. Amer. Soc. Hort. Sci. 56:122-128.

Williams, J.H., Friedman, W.E. and Arnold, M.L. 1999. Developmental selection within the angiosperm style: Using gamete DNA to visualize interspecific pollen competition. P. Natl. Acad. Sci. USA 96:9201-9206. 


\section{Figures}
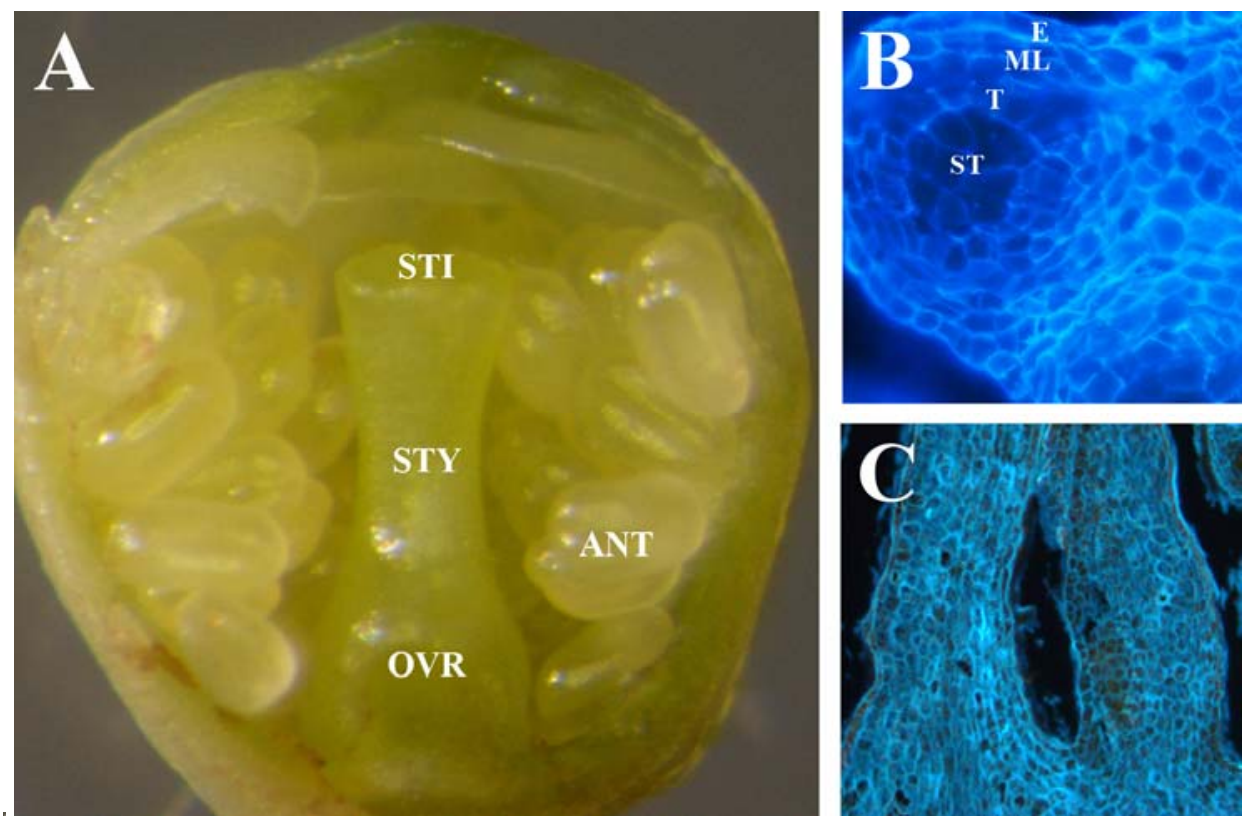

Fig. 1. Flower bud stage of development during dormancy in sweet cherry cv. "Bing" (A). Transverse sections of anther (B) and ovary section (C).

STI, stigma; STY, style; OVR, ovary; ANT, anthers; ST, sporogenous tissue; T, tapetum; ML, middle layers; E, epidermis.

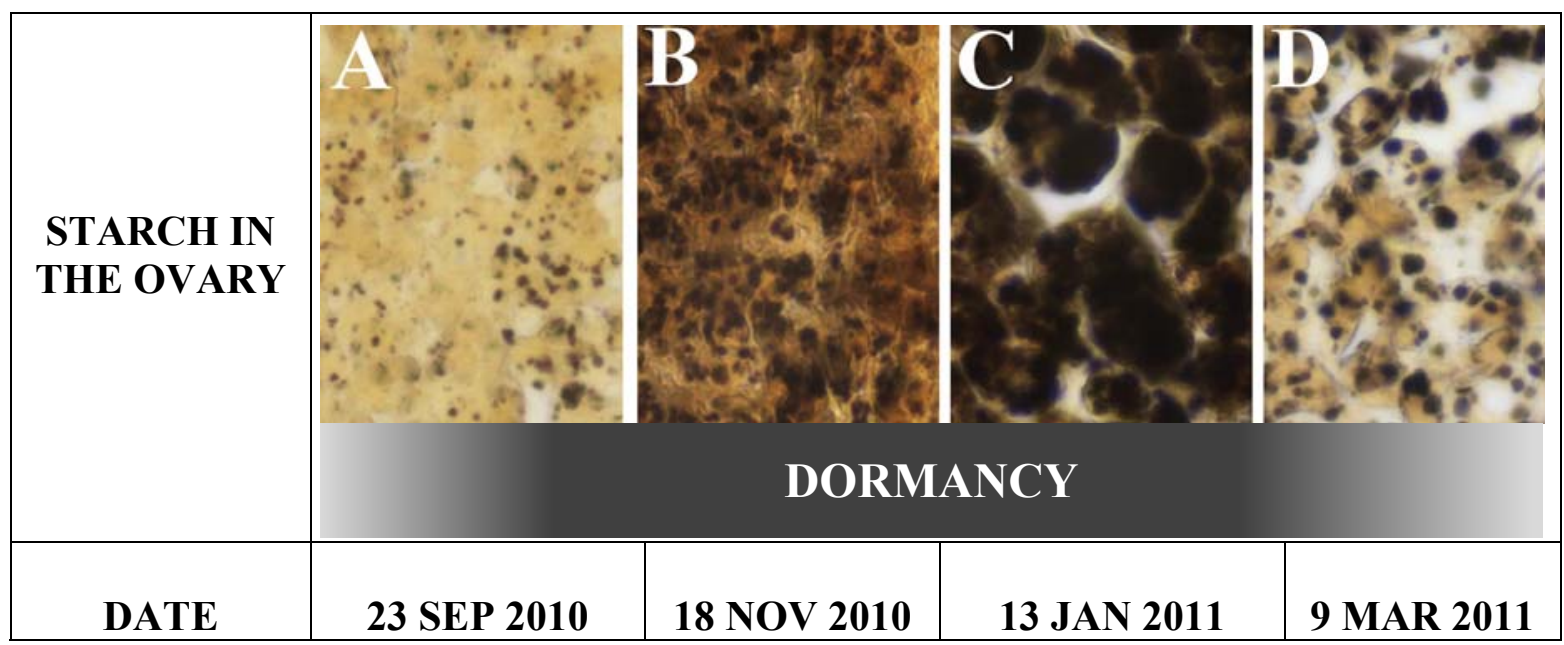




\begin{tabular}{|c|c|c|c|c|}
\hline $\begin{array}{l}\text { CHILLING } \\
\text { HOURS }\end{array}$ & $\mathbf{0}$ & 178 & $\begin{array}{c}1073 \\
\text { (Chilling fulfilment) }\end{array}$ & \\
\hline $\begin{array}{c}\text { STARCH } \\
\text { CONTENT } \\
\text { ( } \sum \text { Optical } \\
\text { density) }\end{array}$ & $3639 \pm 1223^{a}$ & $17286 \pm 7385^{a b}$ & $140928 \pm 15932^{b}$ & $26390 \pm 3711^{c}$ \\
\hline
\end{tabular}

Fig. 2. Starch content in the ovary during dormancy in flowers of sweet cherry cv. "Bing" and number of chilling hours accumulated at sample dates. Traces of starch at dormancy establishment (A). Progressive starch accumulation during dormancy (B, C). Starch content at bud burst (D). Mean \pm SE of the average values. Different letters indicate significant differences $(\mathrm{P}<0.05)$ using Duncan's multiple range test. 